\title{
BODY COMPOSITION CHANGES IN ADULT FEMALES AFTER LIFESTYLE INTERVENTION ARE INFLUENCED BY THE NYD-SP18 VARIANT
}

\author{
Pavel Suchánek ${ }^{1,2}$, Věra Lánská ${ }^{1}$, Jaroslav Alois Hubáček ${ }^{1}$ \\ ${ }^{1}$ Centre for Experimental Medicine, Institute for Clinical and Experimental Medicine, Prague, Czech Republic \\ ${ }^{2}$ Faculty of Public Health and Social Studies, South Bohemia University, České Budèjovice, Czech Republic
}

\begin{abstract}
SUMMARY
Aim: The study focuses on the analysis of the possible relationship between a common NYD-SP18 (rs6971091, G >A) gene polymorphism and weight loss after lifestyle intervention (combined dietary intake and physical activity) in overweight/obese females.

Methods: We genotyped 139 unrelated non-diabetic Czech females ( $49.5 \pm 13.3$ years, average BMl at baseline $\left.32.2 \pm 4.6 \mathrm{~kg} / \mathrm{m}^{2}\right)$. Biochemical and anthropometrical measurements were performed before and after ten weeks of lifestyle intervention.

Results: The mean weight loss achieved was $4.7 \pm 3.1 \mathrm{~kg}(\mathrm{p}<0.01)$. Carriers of the NYD-SP18 GG $(\mathrm{N}=75)$ genotype lost significantly more body fat mass $(p=0.04)$ and gained more active muscle mass $(p=0.037)$ than the carriers of the $A$ allele $(N=64)$. After adjustment of baseline values, both differences remained significant $(p=0.03$ and $p=0.016)$.

Conclusion: Overweight/obese female carriers of the NYD-SP18 rs6971091 GG genotype exhibited a more beneficial response to the intensive lifestyle intervention than others.
\end{abstract}

Key words: females, intervention, NYD-SP18, obesity, polymorphism

Address for correspondence: P. Suchánek, Institute for Clinical and Experimental Medicine, Centre for Experimental Medicine, Vídeňská 1958/9, 14021 Prague 4, Czech Republic. E-mail: pasu@ikem.cz

\section{INTRODUCTION}

Obesity is one of the most common preventable risk factors for cardiovascular diseases, cancer and type 2 diabetes. Obesity can negatively affect self-perception and physical fitness (1). Overweight/obesity results from a positive energy balance, which is caused predominantly by a combination of low levels of physical activity and high energy intake as well as other less discussed but important factors (e.g. sleeping deficit) $(2,3)$.

Body weight is significantly influenced by genetic factors (both common polymorphisms as well as rare mutations), and twin studies estimate that up to $60 \%$ of BMI variability is attributable to genetics. Similarly, susceptibility to weight loss interventions seems to be under genetic control (4).

Variants within the NYD-SP18 gene have been identified using fine mapping of a region on chromosome 7 that is well known for its high obesity LOD score. In the National Heart, Lung and Blood Institute (NHLBI) Family Heart Study, the effect of NYD-SP18 variants on obesity was even greater (5) than that of one of the FTO variants with a well-established impact on body weight (6). However, no studies to date have examined the effect of NYD-SP18 variants on the efficacy of weight loss interventions.

We present the results of a short-term intervention study on female volunteers, which focuses on the possible effect of the NYD-SP18 genetic variant on body weight loss.

\section{MATERIALS AND METHODS}

\section{Subjects}

A population of 139 unrelated overweight and obese Czech Caucasian sedentary adult females, recruited via an advertisement on a lifestyle website and in a women's journal, was analysed. All volunteers were examined in a medical research centre. Females (with abdominal-type obesity) were selected according to the criteria of having a BMI over $28.6 \mathrm{~kg} / \mathrm{m}^{2}$ and aged between 25 and 65 years (mean age $49.5 \pm 13.3$ years). Exclusion criteria applied to known inflammatory or metabolic diseases (diabetes, thyroid gland disease, any other endocrine disorders, autoimmune diseases, and any chronic inflammation or neoplastic disease).

\section{Procedures and Dietary Habits}

Study participants underwent a ten-week lifestyle modification programme (7). Dietary intervention (comprised of a weekly, supervised dietary record) was aimed at adjusting energy intake to the amount recommended for the relevant age $(\max .7,500 \mathrm{~kJ} /$ day, achieved mean was $7,186 \mathrm{~kJ} /$ day), and decreasing animal fat and dietary cholesterol intake. Eating more fruits and vegetables was also encouraged. Dietary intervention (comprised of a weekly, supervised dietary record) was aimed at lowering energy intake (to age-adjusted recommended values) as well as decreasing animal fat intake. Additionally, the volunteers participated 3 times per 
week in a supervised 1-hour training session at a fitness centre, and 2 more sessions per week (cycling, jogging or brisk walking) were recommended (at least one session was performed by all individuals). All these activities included an aerobic exercise component - the participants were supervised (and advised) to maintain their heart rate between 115 and 145 beats (according to age) per minute during the 60 -minute exercise session. Heart rates were continuously recorded telemetrically (Sport Tester S 410, RS 400, Polar Electro, Oy, Kempele, Finland). Probands had their lipid and anthropometrical parameters and blood pressure determined at baseline and at the end of the study.

Changes in diet were calculated from dietary records before intervention and at the last week of intervention.

\section{Laboratory Analysis}

Genomic DNA was extracted from the patients' peripheral white blood cells. The NYD-SP18 SNP rs6971091 polymorphism was genotyped using polymerase chain reactionrestriction fragment length analysis. The chemicals used were purchased from Fermentas International Inc., Burlington, Ontario, Canada, and the Polymerase Chain Reactions (PCR) were performed using the DYAD Disciple PCR machine from MJ Research (Waltham, MA, United States). DNA was amplified in a total volume of $25 \mu \mathrm{L}$ using the oligonucleotides $5^{\prime}$ cet tgg tca tta get gaa tga gaa get and 5' aag gec tta acc tgg ttc tgc. The PCR product (105 bp) was cut with 5 units of the HindIII restriction enzyme. Restriction fragments of $79 \mathrm{bp}$ and $26 \mathrm{bp}$ represented the A allele, whereas the presence of an uncut product represented the more common $\mathrm{G}$ allele.

Plasma triacylglycerols, total cholesterol and cholesterol in high-density (HDL-C) and low-density (LDL-C) fractions were measured enzymatically by standardised procedure, using the Cobas Mira analyzer (Hoffman-LaRoche).

\section{Anthropometric Measurements}

Body weight was measured using an electronic weight scale (scaled to the nearest $100 \mathrm{~g}$ ), which was placed horizontally and calibrated before each weighing session. Height was measured

Table 1. Characteristics of study participants before and after intervention (mean $\pm S D$ )

\begin{tabular}{|c|c|c|c|}
\hline & \multicolumn{3}{|c|}{ NYD-SP18 rs6971091 } \\
\hline & Before & After & p-value \\
\hline $\mathrm{N}$ & \multicolumn{2}{|c|}{139} & \\
\hline Weight $(\mathrm{kg})$ & $91.3 \pm 14.1$ & $86.7 \pm 14.7$ & $<0.001$ \\
\hline $\mathrm{BMI}\left(\mathrm{kg} / \mathrm{m}^{2}\right)$ & $32.2 \pm 4.6$ & $29.9 \pm 6.0$ & $<0.001$ \\
\hline Total fat mass ( $\%)$ & $42.1 \pm 6.4$ & $38.5 \pm 5.4$ & $<0.001$ \\
\hline Muscle mass & $52.4 \pm 5.9$ & $53.5 \pm 5.8$ & $<0.01$ \\
\hline $\mathrm{Hip}(\mathrm{cm})$ & $114.4 \pm 11.2$ & $107.5 \pm 12.7$ & $<0.001$ \\
\hline Waist (cm) & $103.0 \pm 13.4$ & $94.3 \pm 13.0$ & $<0.001$ \\
\hline Total cholesterol (mmol/L) & $5.3 \pm 1.2$ & $4.9 \pm 1.0$ & $<0.01$ \\
\hline Triglycerides (mmol/L) & $1.51 \pm 0.78$ & $1.38 \pm 0.82$ & ns \\
\hline HDL-cholesterol (mmol/L) & $1.49 \pm 0.42$ & $1.45 \pm 0.39$ & ns \\
\hline Glucose (mmol/L) & $5.67 \pm 1.27$ & $5.48 \pm 1.1$ & $<0.01$ \\
\hline
\end{tabular}

Table 2. Characteristics of study participants before intervention (mean \pm SD) using the NYD-SP18 rs6971091 genotype. No significant differences were detected

\begin{tabular}{|l|c|c|c|}
\hline \multirow{2}{*}{} & \multicolumn{2}{|c|}{ NYD-SP18 rs6971091 } \\
\cline { 2 - 4 } & GG & GA & AA \\
\hline $\mathrm{N}(\%)$ & $75(54.0 \%)$ & $57(41.0 \%)$ & $87.2 \pm 13.4$ \\
\hline Weight $(\mathrm{kg})$ & $89.6 \pm 13.7$ & $93.3 \pm 12.7$ & $31.5 \pm 3.8$ \\
\hline BMl $\left(\mathrm{kg} / \mathrm{m}^{2}\right)$ & $32.2 \pm 4.6$ & $32.2 \pm 4.0$ & $39.8 \pm 6.4$ \\
\hline Total fat mass (\%) & $41.4 \pm 5.2$ & $42.2 \pm 4.6$ & $52.2 \pm 7.0$ \\
\hline Muscle mass (\%) & $52.3 \pm 6.4$ & $53.7 \pm 5.8$ & $111.3 \pm 7.2$ \\
\hline Hip (cm) & $114.0 \pm 9.6$ & $114.5 \pm 7.2$ & $99.4 \pm 12.0$ \\
\hline Waist (cm) & $103.6 \pm 13.1$ & $104.6 \pm 10.3$ & $5.3 \pm 0.7$ \\
\hline Total cholesterol (mmol/L) & $5.2 \pm 1.1$ & $5.3 \pm 0.8$ & $1.35 \pm 0.60$ \\
\hline Triglycerides (mmo//L) & $1.53 \pm 0.69$ & $1.60 \pm 0.96$ & $1.51 \pm 0.18$ \\
\hline HDL-cholesterol (mmol/L) & $1.45 \pm 0.35$ & $1.46 \pm 0.38$ & $5.37 \pm 0.55$ \\
\hline Glucose (mmol/L) & $5.96 \pm 1.99$ & $5.85 \pm 1.28$ & \\
\hline
\end{tabular}


with a stadiometer to the nearest $0.5 \mathrm{~cm}$. Waist (defined as the narrowest diameter between the xiphoid process and iliac crest) and hip (defined as the widest diameter over the greater trochanters) circumferences were measured to an accuracy of $0.5 \mathrm{~cm}$. The waist-to-hip ratio (WHR) and BMI were calculated from obtained measurements. Diastolic and systolic blood pressure were measured after 10 minutes in a sitting position with an average of 3 readings on the right arm using an automated blood pressure unit (Automated sphygmomanometer BP-203 NA, Nippon Colin Co., Ltd). Body composition, basal metabolic rate and estimated average requirements were determined by impedance analysis using a Bodystat analyzer (1500 MDD; Bodystat, Isle of Man, UK). A trained nurse performed all measurements.

\section{Statistic Analysis}

The differences in lipids, anthropometrical parameters, body composition, basal metabolic rate and estimated average requirements were evaluated by performing an ANOVA test. Because of the low number of AA homozygotes $(\mathrm{N}=7)$, this group was joined to CA heterozygotes for the purpose of this study, and both groups were evaluated together for all parameters. All data are presented as a mean $\pm \mathrm{SD}$. Differences are considered to be statistically significant if $\mathrm{p}<0.05$.

\section{RESULTS}

Basic characteristics of volunteers before the intervention are summarised in Table 1. Analysed parameters were not associated with examined polymorphism at baseline (Table 2).

There was a significant positive change in the anthropometrical parameters of interest after the intervention. Average BMI decreased $(p<0.01)$ and fat mass also fell significantly. We documented a high inter-individual variability in response to the intervention; the most significant body weight decrease was -15.5 $\mathrm{kg}$, and the lowest was in fact a gain of $+2.0 \mathrm{~kg}$.

The call rate of the NYD-SP18 rs6971091 variant was $100 \%$. The Hardy-Weinberg test confirmed the independent segregation of individual genotypes $(\mathrm{p}=0.37)$; the frequency of the minor A allele (0.26) was similar to previously published results (5) and did not significantly differ from the general population (Hubáček, unpublished observation).

Baseline measurements showed that minor AA homozygotes had slightly lower BMIs, waist and plasma glucose, but the differences did not reach statistical significance.

The NYD-SP18 rs6971091 variant was a significant determinant of the success of the intervention. Despite the fact that there were no differences in body weight (or BMI) reduction, carriers of the GG genotype reduced their fat mass significantly more $(-5.0 \pm 3.3 \mathrm{~kg} ; \mathrm{p}=0.037)$ than carriers of at least one A allele $(-3.7 \pm 3.5 \mathrm{~kg})($ Table 3$)$.

Vice versa, carriers of the GG genotype showed larger increases in total muscle mass (Table 3$)$ than A allele carriers ( $1.6 \pm 4.4 \mathrm{~kg}$ vs. $0.4 \pm 1.1 \mathrm{~kg} ; \mathrm{p}=0.04)$, and the difference remained statistically significant $(\mathrm{p}=0.016)$ after adjustment for matching baseline values.

Changes in other anthropometrical and biochemical parameters were not dependent on NYD-SP18 genotypes.

\section{DISCUSSION}

Our study is the first to document the important role of the common NYD-SP18 gene variant in determining body composition changes after an intensive ten-week lifestyle intervention in overweight/obese females. Homozygotes for the rs6971091 NYD-SP18 major $\mathrm{G}$ allele benefited significantly more from the intervention than carriers of the minor A allele.

NYD-SP18 is one of the genes that has been suggested as a candidate for determining obesity. The gene is located in a locus that is known for its high LOD score for obesity. So far, the putative association between rs6971091 NYD-SP18 variants and BMI has been reported in one original study; (5) however, they have not been confirmed in any further studies. Importantly, no studies focusing on obesity treatment efficacy have been performed on either adults or on children/adolescents.

Intervention studies have tested dozens of genes in an attempt to identify a genetic background that could contribute to weight loss after intervention. Unfortunately, a number of factors make intervention studies difficult to compare: differences in dietary changes (caused both by recommendations and patient compliance); the intensity and frequency of physical activity; the pre-selection of participants; and the relatively low number of individuals included (often less than 100 participants). Therefore, it is not surprising that most of the studies published to date have recorded inconclusive results and are difficult to replicate (8-14).

On an identical group of individuals, we previously analysed the effect of some other candidate genes on the possible effectiveness of a short-term intensive lifestyle intervention on anthropometrical and biochemical parameters. We detected positive gene-intervention interaction in the case of angiotensinconverting enzyme (7), AHSG (9) and apolipoprotein A5 (14). However, variants within the genes, such as FTO (8), INSIG-2 (15) and preproghrelin, (16) were not associated with efficacy of the intensive lifestyle intervention.

Despite the strength of our study (on a homogenous group of participants), it has several limitations. First, our results have

Table 3. Significant effects of the NYD-SP18 polymorphism on fat mass decrease and active muscle mass increase. Unadjusted $p$ and $p^{*}$ adjusted for baseline values are given

\begin{tabular}{|l|c|c|c|c|}
\hline \multirow{2}{*}{} & \multicolumn{4}{|c|}{ NYD-SP18 genotype } \\
\cline { 2 - 5 } & GG & $+\mathbf{A}$ & $\mathrm{p}$-value & p-value $^{*}$ \\
\hline $\mathbf{N}$ & 75 & 64 & & 0.040 \\
\hline Total fat mass & $\Delta-5.0 \pm 3.3$ & $\Delta-3.7 \pm 3.5$ & 0.037 & 0.016 \\
\hline Muscle mass & $\Delta+1.6 \pm 4.4$ & $\Delta+0.4 \pm 1.1$ & 0.040 & \\
\hline
\end{tabular}


not been confirmed by another independent study, which seems to be of importance, especially given the relative low number of females who underwent intervention. Moreover, the functional importance of the gene variant's relationship to body weight is not clear. Because NYD-SP18 has been associated with testosterone production, we speculate that it may predominantly influence exercise-based muscle development and formation.

Our results suggest that the rs6971091 NYD-SP18 variant could be a genetic determinant of body composition changes after lifestyle intervention, at least in adult females. Determining whether these results hold true for other population groups and different types of interventions requires further study.

\section{Acknowledgements}

The authors wish to thank all of the study participants.

\section{Conflict of Interest}

The authors declare that they have no conflict of interest.

\section{Sponsorship}

This work was supported by the Ministry of Health of the Czech Republic's development of research organisation project 00023001 (IKEM, Prague, Czech Republic) - institutional support.

\section{Adherence to Ethical Recommendations}

All volunteers signed informed consent forms and agreed to participate in the study, which was approved by the Institutional Ethics Committee.

\section{REFERENCES}

1. Kim JH, So WY. Associations between overweight/obesity and physical fitness variables in Korean women. Cent Eur J Public Health. 2013 Sep;21(3):155-9.

2. Hubáček JA. Eat less and exercise more - is it really enough to knock down the obesity pandemia? Physiol Res. 2009;58 Suppl 1:S1-6.

3. McAllister EJ, Dhurandhar NV, Keith SW, Aronne LJ, Barger J, Baskin $\mathrm{M}$, et al. Ten putative contributors to the obesity epidemic. Crit Rev Food Sci Nutr. 2009 Nov;49(10):868-913.
4. Moleres A, Rendo-Urteaga T, Zulet MA, Marcos A, Campoy C, Garagorri JM, et al.; EVASYON Study Group. Obesity susceptibility loci on body mass index and weight loss in Spanish adolescents after a lifestyle intervention. J Pediatr. 2012 Sep;161(3):466-470.

5. Wilk JB, Laramie JM, Latourelle JC, Williamson S, Nagle MW, Tobin JE, et al. NYD-SP18 is associated with obesity in the NHLBI Family Heart Study. Int J Obes (Lond). 2008 Jun;32(6):930-5.

6. Cheung MK, Yeo GS. FTO Biology and Obesity: why do a billion of us weigh $3 \mathrm{~kg}$ more? Front Endocrinol (Lausanne). $2011 \mathrm{Feb} 22 ; 2: 4$.

7. Suchánek P, Hubáček JA, Králová Lesná I, Pinekerová V, Adámková V. Actigenetic of ACE gene polymorphism in Czech obese sedentary females. Physiol Res. 2009;58 Suppl 1:S47-52.

8. Dlouhá D, Suchánek P, Lánská V, Hubáček JA. Body mass index change in females after short-time life style intervention is not dependent on the FTO polymorphisms. Physiol Res. 2011;60(1):199-202.

9. Suchanek P, Kralova-Lesna I, Poledne R, Lanska V, Hubacek JA. An AHSG gene variant modulates basal metabolic rate and body composition development after a short-time lifestyle intervention. Neuro Endocrinol Lett. 2011;32 Suppl 2:32-6.

10. Moleres A, Rendo-Urteaga T, Zulet MA, Marcos A, Campoy C, Garagorri JM, et al.; EVASYON Study Group. Obesity susceptibility loci on body mass index and weight loss in Spanish adolescents after a lifestyle intervention. J Pediatr. 2012 Sep;161(3):466-470.

11. Stocks T, Angquist L, Banasik K, Harder MN, Taylor MA, Hager J, et al. TFAP2B influences the effect of dietary fat on weight loss under energy restriction. PLoS One. 2012;7(8):e43212. doi: 10.1371/journal. pone.0043212.

12. Hwang IC, Kim KK, Ahn HY, Suh HS, Oh SW. Effect of the G-protein $\beta 3$ subunit $825 \mathrm{~T}$ allele on the change of body adiposity in obese female. Diabetes Obes Metab. 2013 Mar;15(3):284-6.

13. Oguri K, Tachi T, Matsuoka T. Visceral fat accumulation and metabolic syndrome in children: the impact of Trp64Arg polymorphism of the beta3-adrenergic receptor gene. Acta Paediatr. 2013 Jun;102(6):613-9.

14. Suchanek P, Lorenzova A, Poledne R, Hubacek JA. Changes of plasma lipids during weight reduction in females depends on APOA5 variants. Ann Nutr Metab. 2008;53(2):104-8.

15. Hubáček JA, Suchánek P, Lánská V, Pitha J, Adámková V. INSIG2 G-102A promoter variant exhibits context-dependent effect on HDLcholesterol levels but not on BMI in Caucasians. Folia Biol (Praha). 2011;57(4):170-2.

16. Hubacek JA, Adamkova V, Bohuslavova R, Suchanek P, Poledne R, Lanska V. No significant association between A-501C single nucleotide polymorphism in preproghrelin and body mass index or waist-to-hip ratio in central European population. Metabolism. 2008 Jul;57(7):1016-7.

Received September 16, 2014 Accepted in revised form February 6, 2015 